\title{
Intersubject and intrasubject variability in the consumption of alcohol ${ }^{1}$
}

R. J. SENTER, ERHARD O. EIMER, AND CHARLES L. RICHMAN UNIVERSITY OF CINCINNATI

Ad lib alcohol selection level was shown to remain quite stable within individual rats during 26 weeks of access to $6 \%$ EtOH and water. Intersubject variability was high and did not alter systematically over time. The results were taken as contradictory to the hypothesis that history of exposure to, or consumption of, alcohol affects the subsequent level of alcohol consumption, but to indicate that pre-experimental variables strongly affect consumption rate.

Rick \& Wilson (1966) reported that Wistar rats $(N=6)$ increased their intake of alcohol over a six month period of exposure to a water-EtOH choice situation. Myers and Carey (1961) found that forced consumption of alcohol could, under some conditions, result in an increased preference for alcohol, and Myers (1966) holds that "experience with or acclimation to ethanol evokes a preference for the fluid...." (p. 495).

A counterargument to this position has been raised by Williams (1947), a proponent of the view that alcoholism is at least in part a result of genetic factors. Support for this view arises from the observation of large individual differences in rats' ethanol consumption (Williams, Berry, \& Beerstecher, 1949; Mardones, 1960; Senter \& Sinclair, 1967).

In investigating the development of alcohol ingestion patterns, a potential pitfall lies in the fact that exposure history can be confused with consumption history. An organism could, however, be exposed to ethanol for long periods without ever consuming any.

A group of naive rats, when exposed for a prolonged period to a water-ethanol choice situation, may respond in a number of different patterns. (1) If the exposure model of alcoholism is valid, relative alcohol consumption should increase with exposure time. (2) If some pre-experimental variable affects relative alcohol consumption, it would be expected that alcohol consumption would be different for different rats, but relatively stable over time within each rat. It would be expected, consequently, that positive "test-retest" correlations should exist. (3) If consumption history affects subsequent alcohol consumption, an increase in alcohol consumption levels should be greatest for those animals who are initially high drinkers, and lowest for those animals who are initially low drinkers. In statistical terms, an increase of between-subject variability would be expected. These three possibilities can be tested with a single group of Ss.

Method

Twenty female and six male hooded rats were maintained individually in their home cages for 26 weeks. They were, at the onset of the exposure period, 110 days

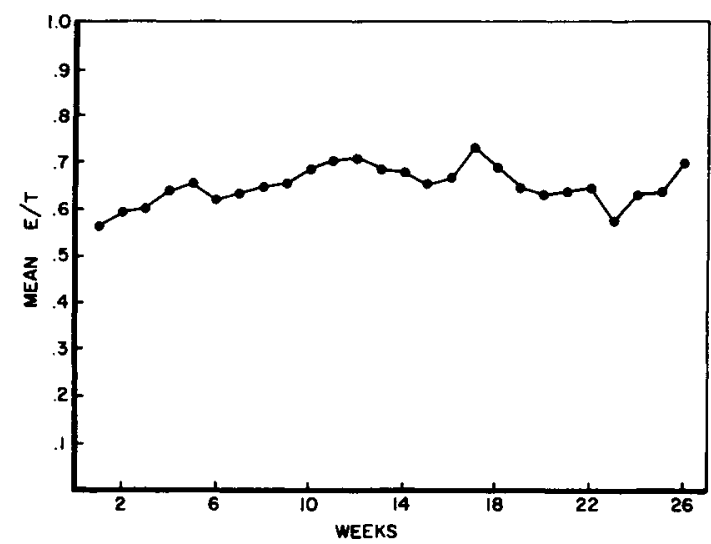

Fig. 1. Weekly mean relative alcohol consumption for each of 26 successive weeks.

old and were experimentally naive. During the exposure period, all rats were allowed constant access to standard laboratory rat chow, water, and a 6\% ethanol solution. The fluids were supplied in two graduated drinking tubes mounted on the front of each cage. The position of the drinking tubes was reversed each day. Daily consumption of water and ethanol solution was recorded. Results

The ratio of $6 \%$ ethanol solution to total liquid consumed per day $(E / T)$ was employed as a measure of relative alcohol consumption. For each of the $26 \mathrm{Ss}$, 26 weekly mean consumption ratios were established. These, in turn, were employed as the data eventually subjected to analysis.

Figure 1 shows mean consumption ratios for all 26 weeks of exposure. An analysis of variance indicates that the mean square associated with time differs significantly from chance expectancy $(F=1.69, \mathrm{df}=25$ / $625, \mathrm{p}<.05$ ), but the linear trend associated with a constant rate of increase in $E / T$ is not significant ( $F=3.17$, df $=1 / 625, p>.05)$.

The mean square associated with $\mathrm{Ss}$ was shown to differ significantly from chance expectancy $(F=49.03$, $\mathrm{df}=25 / 625, \mathrm{p}<.05$ ). To assess this finding more precisely, the $\omega^{2}$ associated with the subject variance was determined. This statistic (Hays, 1966) is an index of the proportion of variance in the dependent variable accounted for by an independent variable. The value of $\omega^{2}$ Y|Ss was found to be .63 , suggesting that approximately $63 \%$ of the total variance can be thought of as being due to individual differences in relative alcohol consumption. 
Figure 2 expresses this finding in a different form, viz., in terms of correlation coefficients between relative consumption data collected during the first week and during each subsequent week. The average correlation coefficient for all 26 weeks (derived after the appropriate $z$-transformation) is +.67 . No systematic decrease in correlation was observed following the third week of exposure. The average of the coefficients subsequent to the third week of exposure is +.65 . The coefficient of determination, $r^{2}$, is .42 , suggesting that $42 \%$ of the individual differences among rats' relative alcohol consumption are associated with variables already present during the first week of drinking.

Figure 3 shows changes in inter-subject variability as a function of time. This figure offers no evidence indicating a systematic increase in variability as a function of time. This finding is inconsistent with the notion that relative alcohol consumption increases as a function of consumption history.

\section{Discussion}

The present study offers some evidence that changes in alcohol intake do not occur by virtue of the mere fact that alcohol has been available, or even that the organism has regularly consumed alcohol in the past. It suggests that alcohol intake rate changes remarkably little over time, within an unmanipulated organism, but may differ widely from one organism to another. Within a learning framework, it seems difficult to ac-

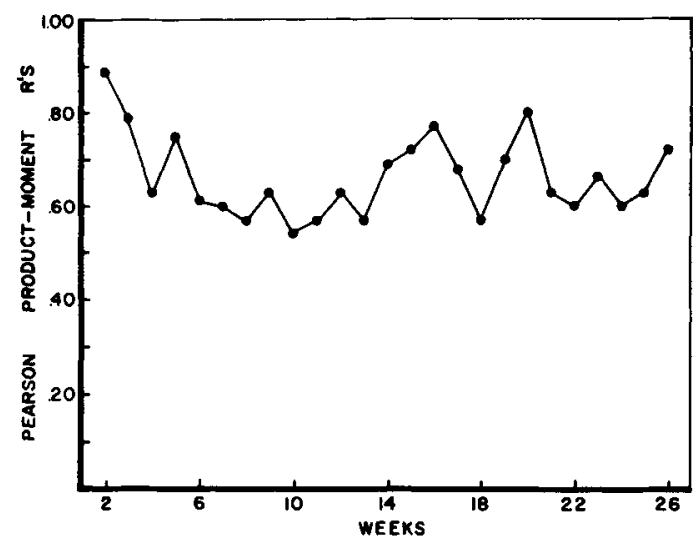

Fig. 2. Pearson Product Moment correlation coefficients between the weekly mean relative alcohol consumption of the first week and each of the subsequent 25 weeks of access to water and alcohol solution.

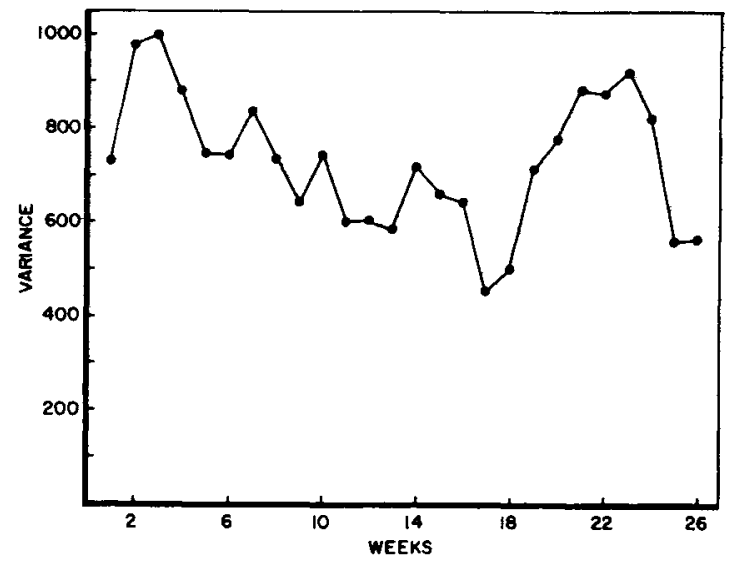

Fig. 3. Variances of weekly relative alcohol consumption for each of 26 successive weeks.

count for how a variable (viz., $E / T$ ) could reach as high a level of dispersion in a group of naive animals, as was the case here, in less than one week, and should then remain relatively unaltered. The present study indicates that relative alcohol consumption rate is characterized by high individual differences and high intraindividual stability over long periods of time. It fails to offer support for the notion that relative EtOH consumption is affected differentially by exposure or consumption history.

\section{References}

HAYS, W. L. Statistics for Psychologists, New York: Holt, Rinehart and Winston, 1966.

MARDONES, J. Experimentally induced changes in the free selection of ethanol. In C. C. Pfeiffer and J. R. Smythies (Eds.) International Review of Neurobiology, Vol. 2, New York: Academic Press, 1960.

MYERS, R. D. Voluntary alcohol consumption in animals: Peripheral and intracerebral factors. Psychosomatic Medicine, 1966, 28, 484-497.

MYERS, R. D., \& CAREY, R. Preference factors in experimental alcoholism. Science, 1961, 134, 469.

RICK, J. T., \& WILSON, C. W.M. Alcohol preference in the rat: Its relationship to total fluid consumption. Quart. J. Stud. Alc., 1966, 27, 447-458.

SENTER, R. J., \& SINCLAIR, J. D. Self-maintenance of intoxication in the rat: A modified replication. Psychon. Sci, 1967, 9, 291-292.

WILLIAMS, R. J. The etiology of alcoholism: A working hypothesis involving the interplay of hereditary and environmental factors. Quart. J. Stud. Alc., 1947, 7, 567-587.

WILLIAMS, R. J., BERRY, L. J., \& BEERSTECHER, E. Biochemical individuality. III. Genetotrophic factors in the etiology of alcoholism. Arch. Biochem., 1949, 23, 275-290.

Note

1. This study is a portion of the research carried out under USPHS Grant No. MH 11063-02. 